

\section{Ryerson context}

- 100+ undergraduate and graduate programs, reputed as being career-focused

- 28,000 students, including 2,300 master's and PhD students

- Chang School of Continuing Education has over 70,000 enrollments and 92 certificate programs, 23 of which are distant

- Commuter campus in downtown core 


\section{Library background}

- Collections heavily focused on current, digital content - aim to provide a "just-in-time" collection v. a "just-in-case" collection

- Some Special Collections, centered mainly on photography and design

- Print collection weeded on ongoing basis, modest growth of newly added titles 


\section{How we got there}

- Period of intense growth of graduate programs began in 2003

- Rapid rise in collections budget

- Consequential need to fundamentally change the way we approached collections

- Librarians and staff could not keep pace 


\section{Orders by type since approval plan implementation}

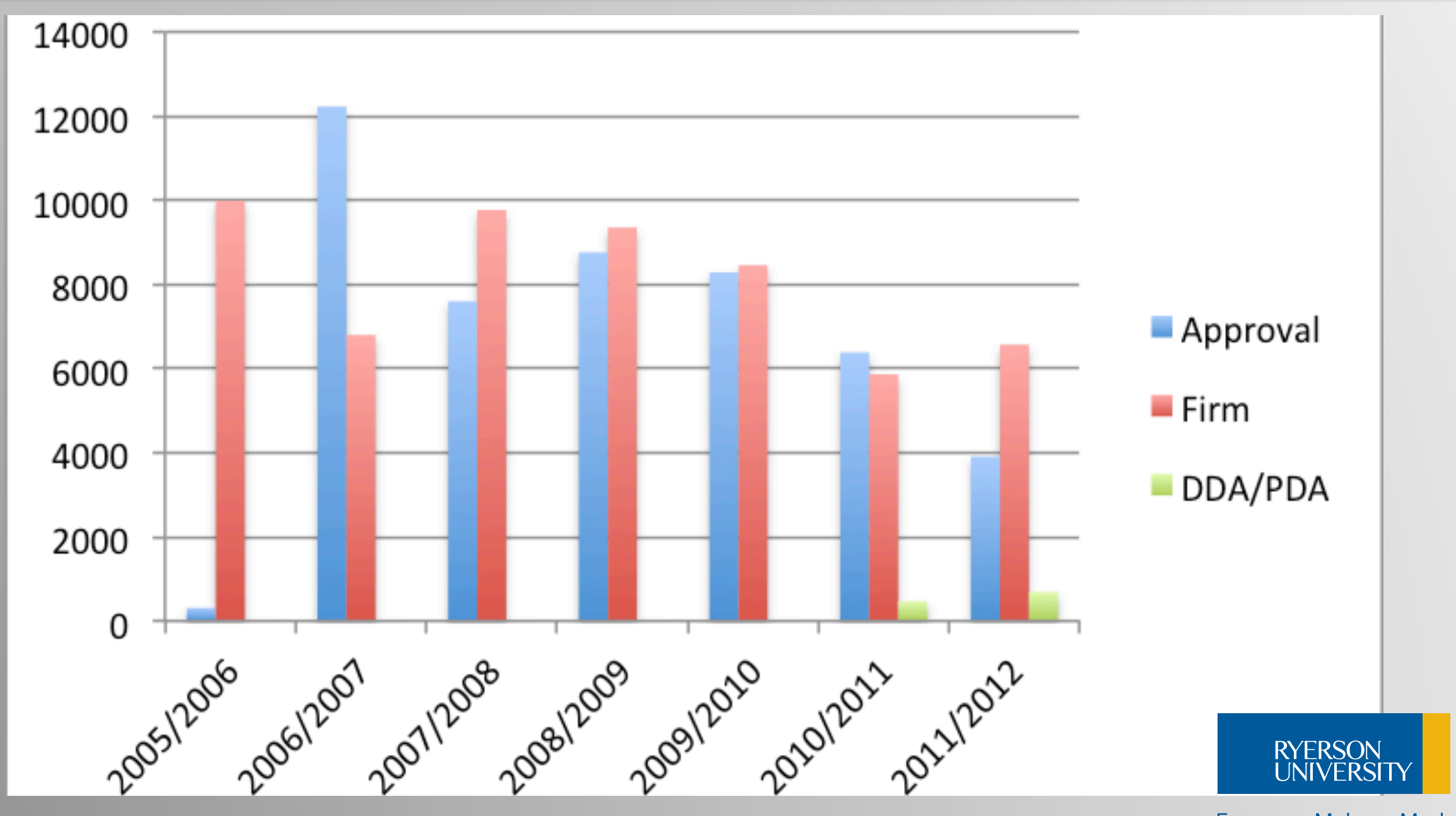




\section{Pilot Phase}

- PDA pilot, Oct 2011 - Mar 2012

- limited to selected publishers - McGraw Hill, Wiley, Elsevier, and 25 University presses

- under \$200, 2009+

- \$49,200 spent

- 688 ebooks purchased, average book price $\$ 71.5$ 


\section{Titles Purchased by Subject}

\section{Titles Purchased by Subject}

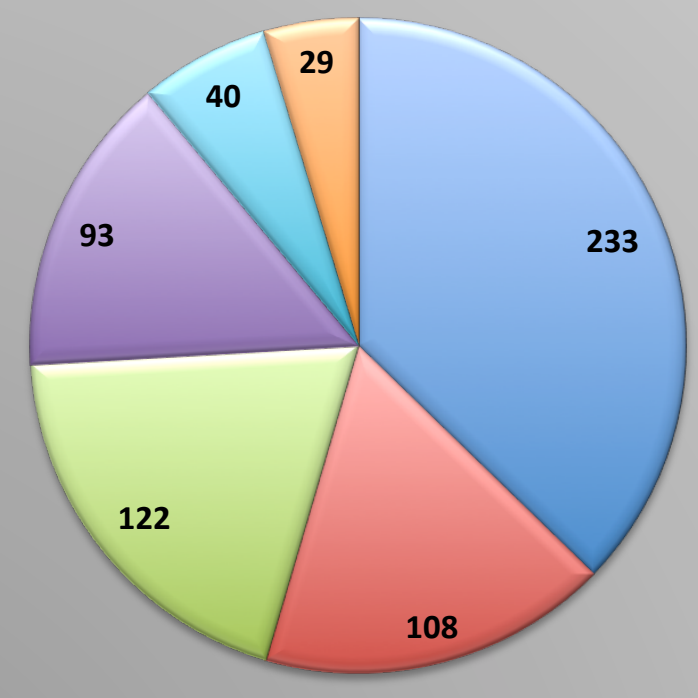

$\square$ Engineering \& Architecture

$\square$ Business

$\square$ Arts $\square$ Social Sciences

$\square$ Others

$\square$ Community Services 


\section{What we learned}

- Duplication Control

- Profiling

- Multi-vendor/platform to focus on content

- flexibility for user licenses

- high usage of ebooks 


\section{Budget woes}

- Budget cuts leaving fewer options

- Need to shore up inflationary costs for continuing resources

- Little choice but to take from monograph base and compensate with OTO funds

- As of $11 / 12$, only base monograph funds for trimmed approval plan

- $12 / 13$ move to bare minimum of firms in favour of expanded DDA 


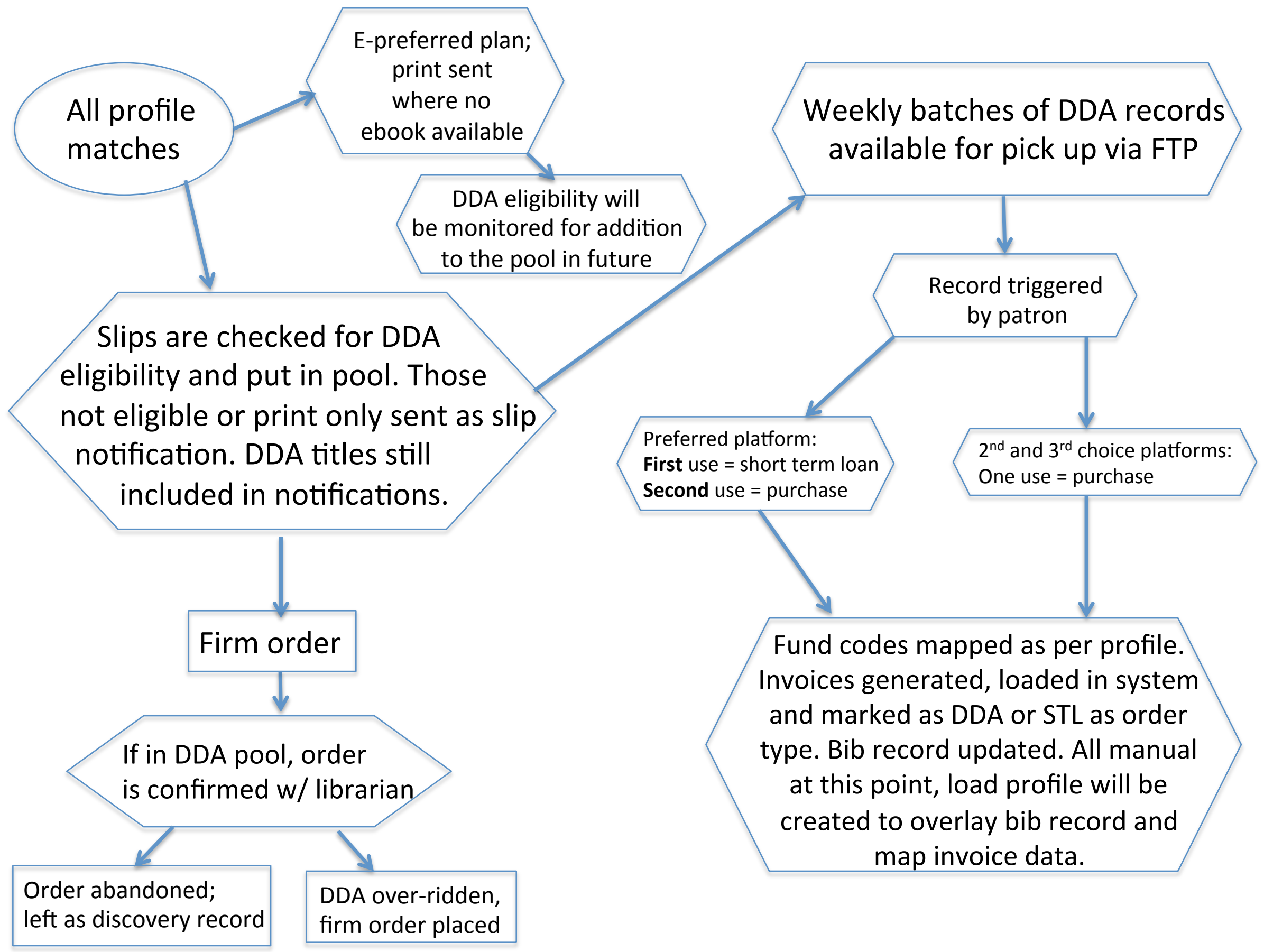




\section{Reception of change}

- Previous pilot projects helped ease in change

- Very little change to librarians workflow

- Staff accustomed to fluctuation 


\section{In house Implementation Considerations}

- Discovery profiles

- Ebook vendor(s) you will use

- License model you will use

- Short term loan v. purchase?

- Enhancements to discovery records?

- Set your price ceilings and warning thresholds

- Mediation options 


\section{Cataloguing Related}

- Tech Specs

- working with vendor to decide on match points in MARC records, etc.

- How often to receive and load discovery records

- Loading Records into catalogue

- Load Profiles or load scripts? How to setup?

- ILS decisions

- Do you want to change your order records to denote DDA?

- Do you need to modify acquisitions module to report on DDA spending? 


\section{Acquisitions}

- Working directly with eBook vendors on top of DDA

- Upgrading licenses for books from SUPO to MUPO

- How to make purchasing decisions to support eBook and DDA?

- Which vendor platform to choose?

- Which license model is appropriate for the type of request?

- How to process DDA orders

- load discovery records

- overlay records for purchased books

- load order records 


\section{One Example: E-Reserves}

- Update workflow to help e-reserves staff identify if books are SUPO or MUPO or NLL

- If SUPO, initiate a workflow to upgrade or investigate other purchases. (Acquisitions staff and subject librarians)

- If NLL, initiate workflow to make chapters available for reserves use. This will be free, or start a separate ordering process

- If the book is DDA and not yet purchased, initiate workflow to purchase the correct license for anticipated demand 


\section{Duplication Control}

- Do you care if you buy both print and e versions of the same book?

- If Yes:

- How will you set up your discovery record profile to prevent?

- Might you have overlap in material from multiple suppliers?

- Ebook packages from consortia or previous purchases?

- How do you let your DDA supplier know what you already have in house? Or do you de-dup when you get your discovery records? If so, how?

- Do you care if you include in your DDA purchases overlaps with your digital subscriptions?

- If Yes:

- How will you make sure to exclude these titles? 


\section{Future Implications}

- STL as the norm

- Impact on package deals

- DDA as mindset

- Print DDA in the future? 